(C) Journal of Applied Mathematics \& Decision Sciences, 4(2), 99-101 (2000)

Reprints Available directly from the Editor. Printed in New Zealand.

\title{
The McNabb Symposium 7-8 February 2000 Auckland, New Zealand
}

\author{
Edited highlights of a 70th Birthday tribute to \\ Alex McNabb, MSc NZ, BA Cant., DSc Well., FRSNZ
}

I am greatly honoured to have been asked to contribute to this auspicious occasion. As part of the theme of my remarks, I will be presenting a meditation on the name Alex McNabb.

Alex, as everyone knows, is the "Big Mac" of New Zealand Applied Mathematics. If "Mac" means "son", this would make him the son of New Zealand Applied Mathematics, but he should be better described as the father. He is, of course, not the first person in New Zealand to distinguish himself in Applied Mathematics but he is pre-eminent within the current generation and deserves the dynastic title of "Father".

I have it on good authority that Nabb means Abbott, and that Alex is therefore descended from a celibate cleric. However, I will pass on quickly to another $\mathrm{McNabb}$, this one fictional and one which emphasises another meaning of "Nab", that is "purloin". The character John MacNab was invented by the author John Buchan to represent a group of three people who had confided in each other that they were passing through difficult times. Each was highly successful in his own chosen sphere of activity but all challenge seemed to have gone out of their lives. They decided that a cure for this ennui might be to take on the pseudonym of John MacNab and to invent daring tasks for themselves. They announced to a number of landowners that they would kill a deer or other game animal on their estates and get away scot-free with their plunder.

Of course they were gentlemen, not poachers, and the booty would be returned to the rightful owners with $£ 50$ for the trouble (if they had lost the challenge they would have paid a higher fee). The John MacNab novel goes on to recount how they went about these feats of daring, how they met interesting characters on the way and how in the end they overcame their taedium vitae and found happiness where this had not been expected.

Becoming a mathematician is also a response to a need for challenges, not to overcome the boredom of the wealthy for a short time, but to devote oneself to a lifetime of solving problems much more demanding and profound than those encountered by a recreational robber. The life of a mathematician, though essentially solitary, often involves contact with interesting characters and happiness can come out of it in ways that were not always as expected. 
I would like to say a little about a change of culture that I have observed over the last 40 or 50 years. There was a time when young people respected the accumulated skills and knowledge of older people - that is the accumulated wisdom - more than I think they do today. Part of modern political correctness is to regard all people as equal independent of what are called "ageist" considerations.

Of course all people are equal - whoever said they weren't? But people have different roles and functions. It is the social responsibility of people, as they become older, to preserve the knowledge they have learnt from their own elders and acquired through their own discoveries. It is also their responsibility to pass this on to later generations. The young have no corresponding responsibility but they are well advised to make the most of having experienced colleagues to learn from. They can choose, either to learn from their older colleagues and thus to start their own careers at a more advanced and sophisticated level, or they can handicap themselves.

The old lamented DSIR of which Alex was a prominent part, no longer fits into accepted structures but it was a good model for preserving, maintaining and enhancing received scientific knowledge. Young scientists and mathematicians and more established scientists and mathematicians worked together so as to provide a precious repository of knowledge and to ensure that a suitable environment existed to help the development of the young.

Alex McNabb has received many signs of his recognition by the mathematical sciences profession, including a Fellowship of the Royal Society of New Zealand. Some words that were written about the fictitious John MacNab apply with only a change of name to the person we are honouring here.

"I tell you what, John MacNab is a very remarkable man, a man in a million, and I'm very much inclined to wish him success."

Alex McNabb has always worked in applications but he still values all parts of mathematics. To call him a great New Zealand Applied Mathematician is to pay him a tribute that he deserves. But an equally great tribute that he deserves is to acknowledge that he is a great New Zealand Mathematician. It is in this light that he is recognised by the New Zealand scientific community as an FRSNZ. And it is in this light that I am proud to have him as a colleague and a friend.

Amongst the non-mathematical interests that Alex enjoys, is gymnastics. He has been a gymnast himself, and a successful competitor, and has also served this sport in other ways throughout his life. Is it fanciful to seek a connection between the nimbleness of mind that lies at the heart of the scientific work that Alex has devoted his life to and the nimbleness of body that comes from this particular sport? At very least, keeping oneself reasonably fit is an aid to doing good mathematics, or to doing good "anything else" that needs a clear head and concerted mental effort. But why gymnastics? I think that what a person does with his or her life is determined at a more central level than physical or mental prowess alone.

There is something in the essence of Alex McNabb-ness that determines his style in all areas of his life. Mens funambula in corpore funambulo - an acrobatic mind in an acrobatic body. 
"I tell you what, Alex McNabb is a very remarkable man, a man in a million and I, and all of us, are very much inclined to wish him even further success".

John C Butcher Honorary Research Professor of Mathematics University of Auckland 


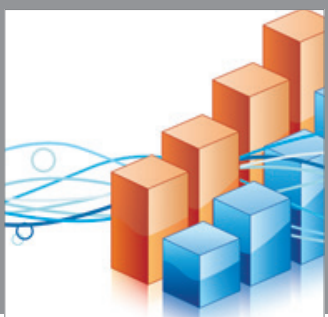

Advances in

Operations Research

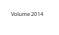

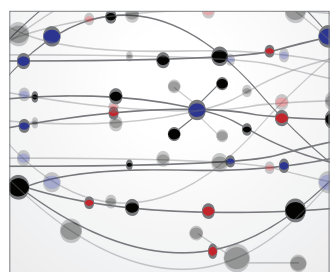

\section{The Scientific} World Journal
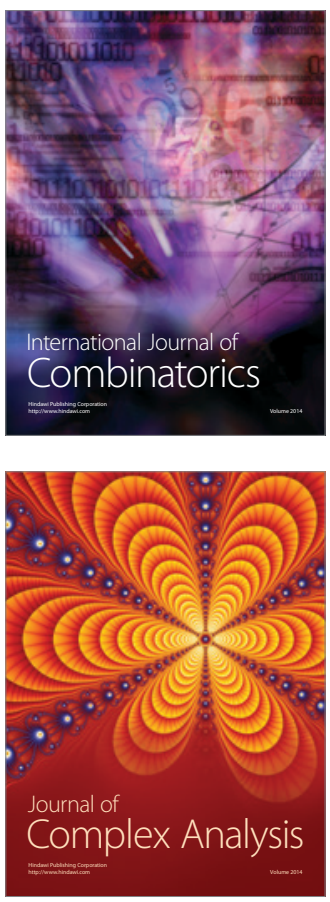

International Journal of

Mathematics and

Mathematical

Sciences
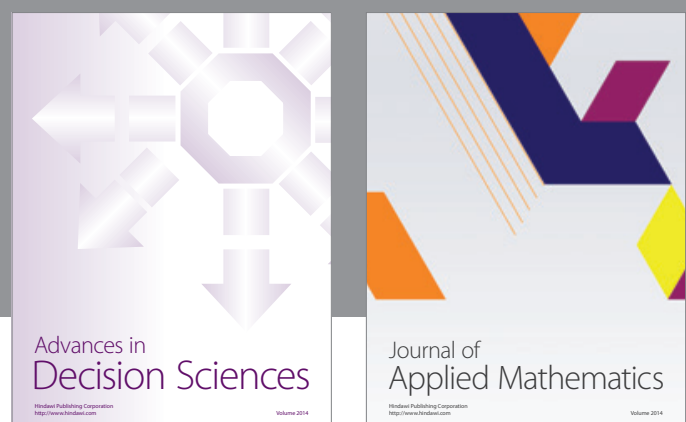

Journal of

Applied Mathematics
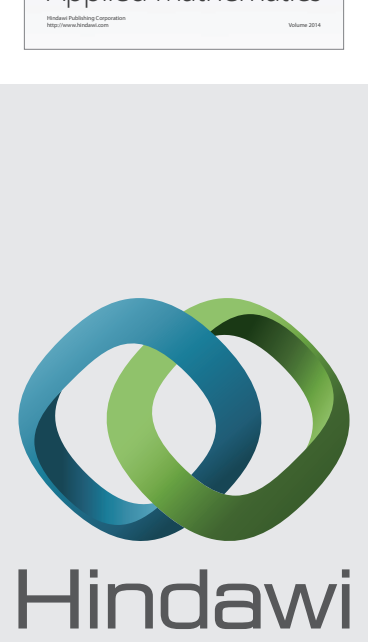

Submit your manuscripts at http://www.hindawi.com
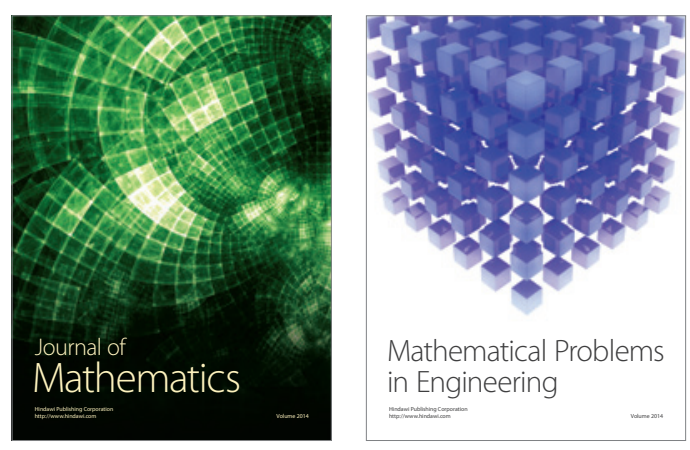

Mathematical Problems in Engineering
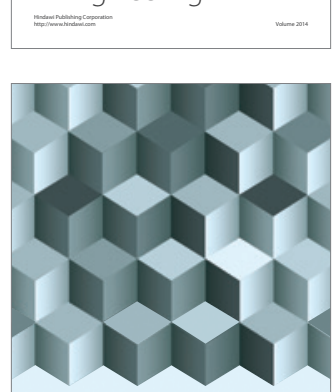

Journal of

Function Spaces
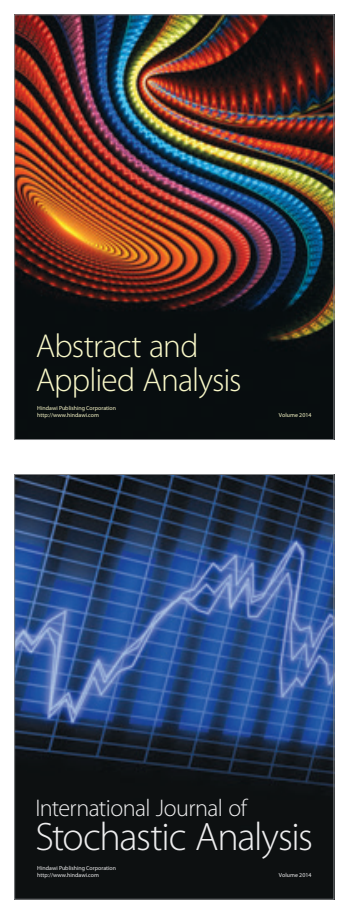

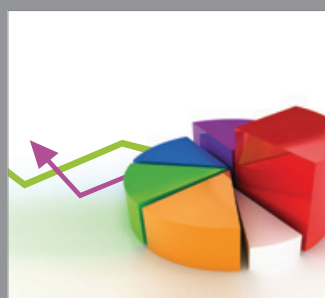

ournal of

Probability and Statistics

Promensencen
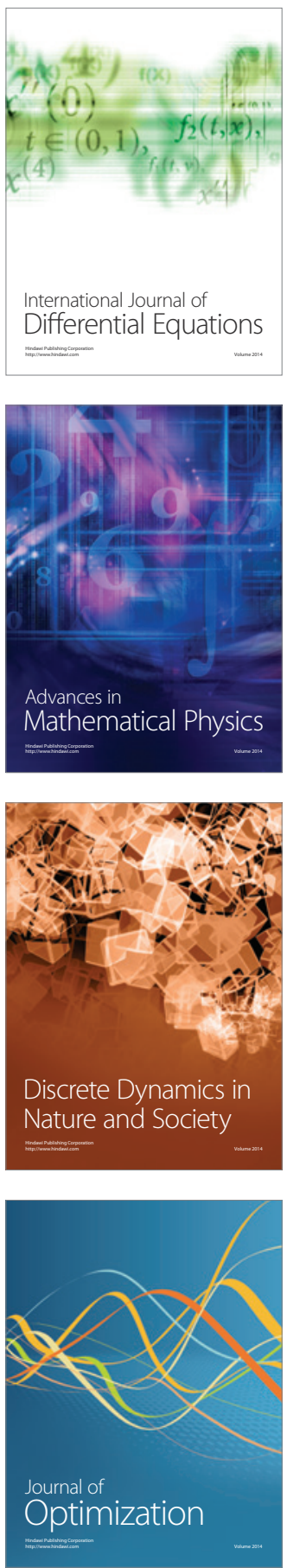